\title{
Kano Model application in new service development and Customer satisfaction
}

\author{
Supriya Mote ${ }^{1}$, Vaishali Kulkarni ${ }^{2}$, Dr. B.E. Narkhede ${ }^{3}$ \\ $\left({ }^{1,2}\right.$ M.Tech, Project Management, Veermata Jijabai Technological Institute, Mumbai-400019,India) \\ $\left({ }^{3}\right.$ Head of Project Management, Veermata Jijabai Technological Institute, Mumbai-400019,India)
}

\begin{abstract}
In today's business environment, to cope up with surroundings, every business has to be agile. Agility must be in correct direction with complete visibility and must have a high speed response to the changes in Market. For being competitive and profitable, businesses can incorporate different strategies. For such strategy creation, we must focus on customer needs and satisfaction. Incorporating this study at the time of planning of such service businesses can definitely improve its efficiency. It is the era of co-creation. This paper presents the Kano model approach to establish and improve the organized retail chain of proprietary items for medium and heavy commercial vehicles. A qualitative survey was done to 43 truck drivers to identify current problems faced by them while on a long haul route travels and what services they expect on highways. Data gathered was converted into the Kano questionnaire and answered by 138 respondents. Kano model helps to differentiate needs, Desires and basic requirement of customers.
\end{abstract}

Keywords: Marketing Strategy, Customer Satisfaction, Market Segmentation, positioning

\section{Introduction}

To survive in an extremely competitive and flexible business environment, companies are becoming more agile towards responding to customer needs with rapid technological shifts and increasing utility of products and services. For coping up with the competitors and satisfying need of customers, companies must come up with new services and products.

New service development is an inter-linked sequence of information processing tasks where knowledge of customer needs is translated into final product or service design. It is not only powerful business activity but also very difficult to develop. New products or services are needed for the long term survival and growth of any firm. Due to paradigm shift from mass marketing to target marketing, Companies now are using STP (Segmentation-Targeting-Positioning) approach for marketing. Creativity incorporation in new service and product development is an effective marketing strategy. Companies are using this creativeness to achieve their goals, vision and production of new product and services. Every new entrant needs to be very specific and creative to get hold of a first mover advantage when launching their product or service $[1,2,3]$.

Success in New service development is a critical management issue particularly in technology-driven firms. Managers working on improvement and design of these new services have a very little secondary data available related to his creative idea and the lookout of customers towards their new service. Market knowledge and marketing proficiency play the main role in the outcome of a new Service. Projects which were strong are market oriented activities that were undertaken proficiently (market assessment, market research and insights, test market, market launch, market segmentation) [5, 6]. This paper gives some of the insights related to new service development using kano approach.

In India, Transport sector is important but sufficient work is not yet done for it. The issues faced by truck drivers such stoppages in journey due to sudden failure of spare parts, bursting of tyres or small accident due to which truck needs immediate maintenance and spares, takes a lot of time to get resolved if proper help is not provided at right time. This affects the operating efficiency as well as reduces profit of transport companies and sometimes goodwill of companies gets harmed. Along with this, truck drivers face problems for hygienic washrooms, good quality food and restrooms for a proper sleep. Market survey shows that most of the drivers get only 2 to 3 hours sleep per day. A study conducted by All India Transport Welfare Association (AITWA), also estimated that, in 2012, around 26, 000 people died as a result of drowsy driving. Though all these problems seem to be very unimportant but they make a huge impact on one's personal life and profit of businesses.

So there is a possibility for a new business model to succeed in Indian market. This proposed business model is a combination of sales of FMCG products for M\&HCV and providing services along with this. With the help of new organized retail chain, established all over India for the spares of commercial vehicles which will include fast moving spares like tyres, clutch, engine oils, filters and batteries. This will be a differentiated model as it will give a platform to specific brands to sell their products in a shop. This retail chain will be established in PAN India with a similar services provided in all the outlets with a common databases of previous 
servicing and repairs of trucks. There are branded stores on highways but they do not provide all these facilities as a one stop solution to customer. According to service providers' perspective, incorporating customer involvement into process of service development gives enormous benefits, such as highly satisfied customer, launch management and reducing the services which are not attracted by customer and will be of waste if incorporated in model $[8,9,10]$. So, this study will aid to the current service providers on highway to improvise their market share and profit and those who want to enter into this market. For creating a value for this new business model, first of all it was necessary to segment the target customer and need assessment study. Along with preparation of Kano model, we have also done the project feasibility study.

\section{Kano Model Concept}

Kano requirement model is the user satisfaction model based on product quality feature, using a nonlinear (two dimensional) way to measure customer's perceptions, mainly to identify customers delight and customer disgust when an attribute is present and absent respectively. This model was proposed by Professor Noriaki Kano [7]. It uses an orthogonal axis system to describe the relationship between customer satisfaction (delight) and product function and features as shown in Figure 1. Kano requirement models are divided into the following four categories based on user requirements:

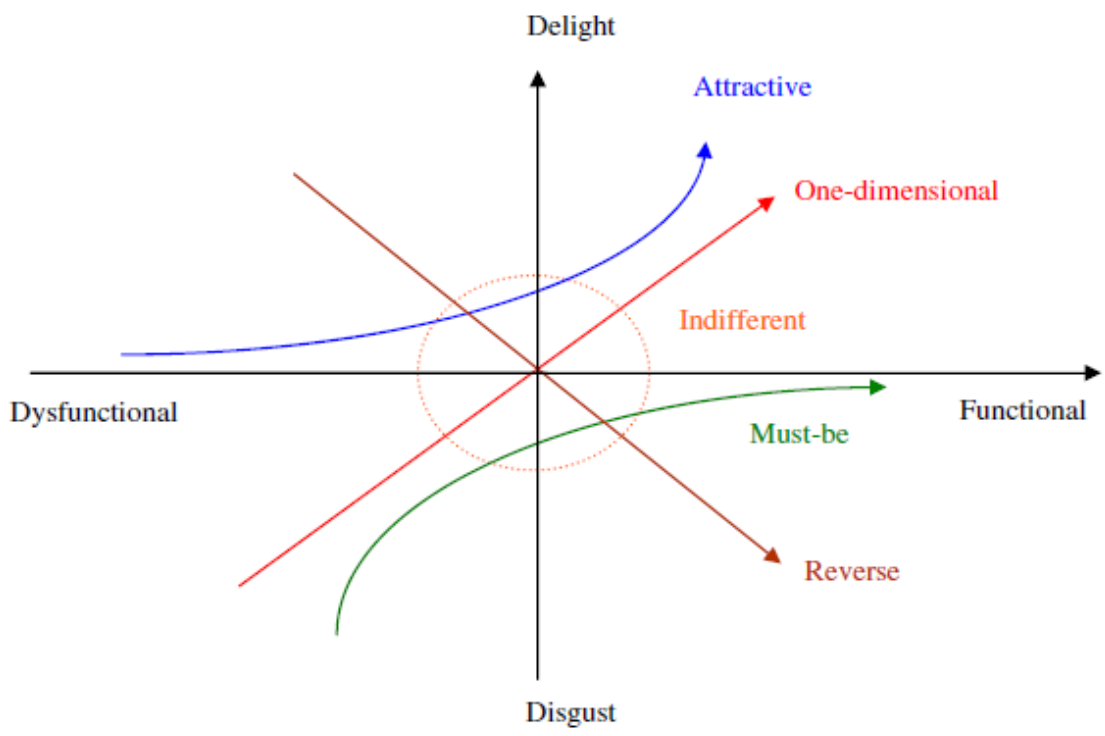

Figure 1 : Kano Model

- Must-be (M): Attributes categorized in this category consists of the preliminary criteria of product since customers will be extremely unhappy if it is not provided. However, provision of these attributes doesn't increase satisfaction rate of customers. It is taken as a granted attribute.

- One-Dimensional (O): Attributes categorized in this category will increase satisfaction level and its absence will lead to increase dissatisfaction level. This type of attribute gives loyalty of customers.

- Attractive (A): Attributes that comes under this category are basically the differentiator of services to be provided. Its functional presence will be loved by customers and their absence will not cause any harm to satisfaction. These are the true delighters.

- Reverse (R): Attributes that falls in this category must be removed as these attributes are harmful to the customer satisfaction and its dysfunctional absence will be appreciated.

- Indifferent (I): Attributes within this category neither contribute in satisfaction nor in dissatisfaction of customer.

- Questionable (Q): this outcome indicates that either the question is wrong or response is illogical.

\section{Research Methodology}

For every successful research there must be a methodology followed. Methodology used for this research is as shown in figure 2. First of all, the basic understanding of business model is brainstormed with the help of experts, wherein they suggested some attributes to incorporate in the business model and which type of business model is to be used with the help of secondary data available on transportation sector.

For getting a practical understanding, a qualitative survey for the focused group interviews was carried out on 43 respondents and insights from this survey were gathered and based on deep understanding, a kano questionnaire was formulated. 


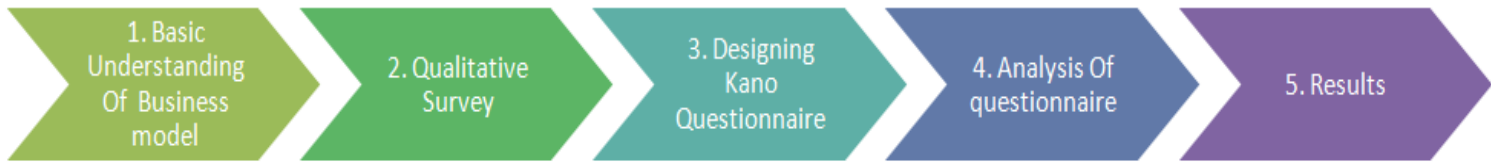

Figure 2: Methodology

\subsection{Kano Questionnaire:}

This new business model will provide both products and services to customers. As the target customers are mainly truck drivers, owners and transport companies, this questionnaire are formulated based on qualitative responses from these targeted customers. This questionnaire is constructed through pairs of customer requirement questions. Each question has two parts: How do you feel if that attribute is present in service (This is a functional form of question) and how do you feel if that attribute is absent in the service(This is dysfunctional form of question) [11]. Five alternatives were provided out of which one alternative was to be selected by customer. Example:

Functional Question: How would you feel if we provide restrooms?

Answers: "I like it"; "It must be there"; "Neutral"; "I can live with it"; "I dislike it".

Dysfunctional Question: How would you feel if we do not provide restrooms?

Answers: "I like it"; "It must be there"; "Neutral"; "I can live with it"; "I dislike it".

Recorded perceptions were then evaluated into quality dimensions on the basis of responses of customers on functional and dysfunctional questions related to different attributes (as shown in Fig.3).

\begin{tabular}{|l|l|l|l|l|l|l|}
\hline \multirow{2}{*}{ Customer Requirements } & \multicolumn{6}{l}{ Dysfunctional (Negative Question) } \\
\cline { 3 - 7 } \multicolumn{2}{|l}{} & Like & Must-be & Neutral & Like & Dislike \\
\hline \multirow{3}{*}{$\begin{array}{l}\text { Functional } \\
\text { (Positive } \\
\text { Question) }\end{array}$} & Like & Q & A & A & A & O \\
\cline { 2 - 7 } & Must- be & R & I & I & I & M \\
\cline { 2 - 7 } & Neutral & R & I & I & I & M \\
\cline { 2 - 7 } & Like & R & I & I & I & M \\
\cline { 2 - 7 } & Dislike & R & R & R & R & Q \\
\hline
\end{tabular}

Table 1 :Evaluation dimensions

If the customer answers to a question "How would you feel if we provide restrooms?" as "I like it"; and to question "How would you feel if we do not provide restrooms?" as "I am neutral"; then combination to answers to both questions provides " $A$ " i.e Attractive Category. Indicating that attribute is an attractive customer requirement from the customer's point of view. If combining the answers yields category I, this means that the customer is indifferent to this service attribute. He does not care whether the attribute is present or not. He is, however, not willing to pay more to this feature if provided. Category Q is for questionable result. Normally, the answers do not fall into this category. Questionable scores show that the question was framed correctly or that the person interviewed didn't understand the question or mark out a wrong answer by mistake. In the study, no service attribute received a Q-rate higher than $2 \%$. If we see the answer in the evaluation table yields category $\mathrm{R}$, this product feature is not only unwanted by the customer but he even expects the reverse [11].

\subsection{Kano model application:}

\begin{tabular}{|c|c|c|c|c|c|c|c|c|c|}
\hline Attributes & Characteristics & $\mathbf{A}$ & $\mathbf{O}$ & $\mathbf{M}$ & I & $\mathbf{R}$ & $\mathbf{Q}$ & Total & Category \\
\hline \multirow[b]{3}{*}{ Sale } & Availability of Spare parts & 83 & 10 & 29 & 17 & 0 & 0 & 139 & $\mathbf{A}$ \\
\hline & Accessories used to decorate trucks & 75 & 3 & 15 & 46 & 0 & 0 & 139 & $\mathbf{A}$ \\
\hline & Music cassettes and CDs & 74 & 19 & 9 & 37 & 0 & 0 & 139 & $\mathbf{A}$ \\
\hline \multirow{10}{*}{ Facilities } & Restrooms & 54 & 54 & 12 & 19 & 0 & 0 & 139 & $\mathbf{O}$ \\
\hline & Secured Parking & 68 & 24 & 29 & 18 & 0 & 0 & 139 & $\mathbf{A}$ \\
\hline & Hygienic washrooms & 22 & 64 & 52 & 1 & 0 & 0 & 139 & $\mathbf{O}$ \\
\hline & Drinking water facility & 11 & 35 & 93 & 0 & 0 & 0 & 139 & $\mathbf{M}$ \\
\hline & Food court & 51 & 54 & 27 & 7 & 0 & 0 & 139 & $\mathbf{O}$ \\
\hline & Food court with all types of food & 31 & 12 & 24 & 69 & 3 & 0 & 139 & I \\
\hline & Room to cook food & 67 & 6 & 7 & 58 & 1 & 0 & 139 & $\mathbf{A}$ \\
\hline & Small saloon like facility & 49 & 5 & 11 & 74 & 0 & 0 & 139 & I \\
\hline & Provides only local type of food & 17 & 3 & 23 & 24 & 72 & 0 & 139 & $\mathbf{R}$ \\
\hline & Mobile Van to support trucks with sudden failure & 74 & 17 & 8 & 39 & 0 & 0 & 138 & $\mathbf{A}$ \\
\hline \multirow{6}{*}{ Service } & Supporting and Trained staff & 69 & 25 & 21 & 24 & 0 & 0 & 139 & $\mathbf{A}$ \\
\hline & Well equipped Garage & 28 & 25 & 77 & 9 & 0 & 0 & 139 & $\mathbf{M}$ \\
\hline & Free cleaning of front glass & 42 & 20 & 15 & 63 & 0 & 0 & 140 & $\mathbf{I}$ \\
\hline & Loyalty cards valid in PAN India & 65 & 3 & 9 & 33 & 29 & 0 & 139 & $\mathbf{A}$ \\
\hline & Prohibition of alcohol & 19 & 4 & 22 & 32 & 62 & 0 & 139 & $\mathbf{R}$ \\
\hline & Special decoration on Festival & 78 & 1 & 16 & 44 & 0 & 0 & 139 & $\mathbf{A}$ \\
\hline
\end{tabular}

Table 2: Kano questionnaire Result 


\subsection{Customer Satisfaction Coefficient:}

Customer Satisfaction Coefficient indicates the extent to which satisfaction increases if a service requirement is met or the extent to which satisfaction decreases if a service requirement is unmet.

\begin{tabular}{|l|}
\hline Customer's Satisfaction coefficient $(\mathrm{CS})=\frac{A+O}{A+O+M+I}$ \\
\hline Customer's Dissatisfaction coefficient $(\mathrm{CD})=\frac{O+M}{(-1) *(A+O+M+I)}$ \\
\hline
\end{tabular}

Table 3 : Calculation of CS and CD

\begin{tabular}{|c|c|c|c|c|}
\hline Attributes & Characteristics & Category & $\begin{array}{c}A+O \\
A+O+M+\end{array}$ & $\frac{-1 *(O+M)}{(A+O+M+I)}$ \\
\hline \multirow[b]{3}{*}{ Sale } & Availability of Spare parts & $\mathbf{A}$ & 0.669 & -0.281 \\
\hline & Accessories used to decorate trucks & $\mathbf{A}$ & 0.561 & -0.129 \\
\hline & Music cassettes and CDs & $\mathbf{A}$ & 0.669 & -0.201 \\
\hline \multirow{10}{*}{ Facilities } & Restrooms & $\mathbf{O}$ & 0.777 & -0.475 \\
\hline & Secured Parking & $\mathbf{A}$ & 0.662 & -0.381 \\
\hline & Hygienic washrooms & $\mathbf{O}$ & 0.619 & -0.835 \\
\hline & Drinking water facility & $\mathbf{M}$ & 0.331 & -0.921 \\
\hline & Food court & $\mathbf{O}$ & 0.755 & -0.583 \\
\hline & Food court with all types of food & $\mathbf{I}$ & 0.316 & -0.265 \\
\hline & Room to cook food & $\mathbf{A}$ & 0.529 & -0.094 \\
\hline & Small saloon like facility & $\mathbf{I}$ & 0.388 & -0.115 \\
\hline & Provides only local type of food & $\mathbf{R}$ & 0.299 & -0.388 \\
\hline & Mobile Van to support trucks with sudden failure & $\mathbf{A}$ & 0.659 & -0.181 \\
\hline \multirow{6}{*}{ Service } & Supporting and Trained staff & $\mathbf{A}$ & 0.676 & -0.331 \\
\hline & Well equipped Garage & $\mathbf{M}$ & 0.381 & -0.734 \\
\hline & Free cleaning of front glass & $\mathbf{I}$ & 0.443 & -0.250 \\
\hline & Loyalty cards valid in PAN India & $\mathbf{A}$ & 0.618 & -0.109 \\
\hline & Prohibition of alcohol & $\mathbf{R}$ & 0.299 & -0.338 \\
\hline & Special decoration on Festival & $\mathbf{A}$ & 0.568 & -0.122 \\
\hline
\end{tabular}

Table 4 :Actual Calculations of CS and CD

A positive CS ranges in value from zero to one; Closer to value one, higher the influence on customer satisfaction. The negative customer satisfaction operates in similar pattern. A value of zero shows that this feature does not cause dissatisfaction if it is not met. In this way, all the evaluated attributes can be represented in a diagram. It is helpful to know their influence on customer satisfaction and dissatisfaction and planning the design for products and service according.

The customer satisfaction coefficients are plotted in diagram. The diagram is divided into four quadrants according to the four types of requirements. Four types are Attractive, Must be, Indifferent and one dimensional. It is clear from the evaluation chart that there are some attributes which if provided, will make highly unsatisfied. Those are prohibition of alcohol and provision of local food only. In our research, we have found out many attributes which comes under attractive category, which means if we incorporate those attributes in our business model, it will give us very positive results. This diagram shows that managers must focus on attributes placed in attractive and one dimensional category. It is not much of importance to pay attention towards the attributes that comes under indifferent category. The attributes nearer to one dimensional and attractive category must be focused and accomplished which will have major impact on satisfaction of customers. Attributes such as food court with all types of food and provides only local food comes under indifferent category which does not provide strong view on satisfaction or dissatisfaction based on these attributes.

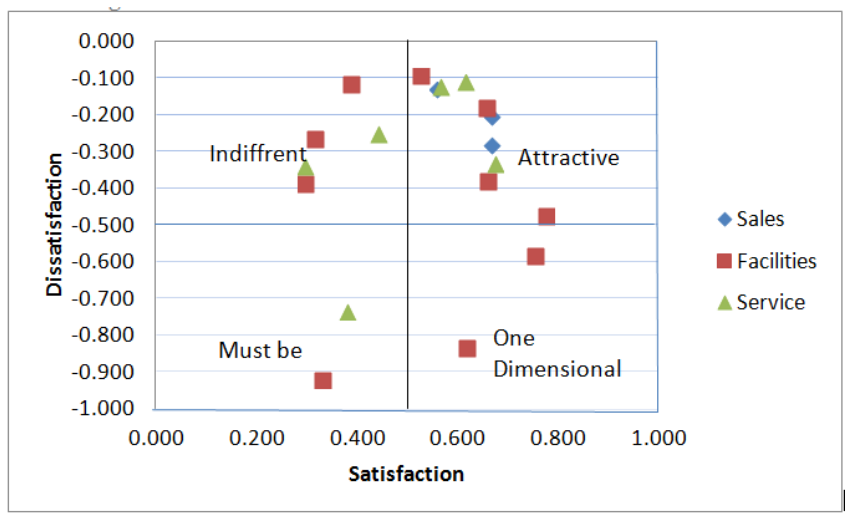

Figure 3: Kano Diagram 


\section{Conclusion}

Kano model concept used in this research paper differentiated the basic, attractive, one dimensional and indifferent attributes for organized retail of proprietary items for medium and heavy commercial vehicle. This research strongly indicated that our target customers are specially looking this retail chain as a "home away from home". They are more attracted to the services like restrooms, hygienic washrooms, inclusion of special festival celebration and proper food provision along with the sales and services related to truck parts. Focusing not only on what the retail must contain, focusing on attractive attributes can also be a effective marketing for the retail. All these needs can be studied in detail and then the final decision of inclusion must be taken for attractive requirements. Our target customer if satisfied well can definitely improve on their operational efficiency and the profit margin for logistic companies.

[1]. Meybodi, Mohammad Z. ,Strategic manufacturing benchmarking. The TQM Magazine.17(3), 2003, 249-258.

[2]. Clark, Kim B. and Wheelwright, Steven C. ,Accelerating the design-build-test cycle for effective product development. International Marketing Review. 11(1), 1995, 32-46.

[3]. Ayag,Z., An integrated approach to evaluating conceptual design alternatives in a new product development environment, International Journal of Production Research, 43(4),2005,687-713.

[4]. Chih-Hsuan Wang, Chu-Wei Wu, Combining conjoint analysis with kano model to optimize product varieties of smart phones: a VIKOR perspective, Journal of Industrial and production Engineering, 31(4),2014, 177-186.

[5]. Ramaseshan B., Caruana Albert, and Loo Soon Pang. ,The effect of market orientation on new product performance: a study among Singaporean firms, Journal of Product and Brand Management. 11(5), 2002, 399-409.

[6]. Kano N. Attractive quality creation under globalization. China Quality, 2002; 9:32

[7]. Chen, C. C. and M. C. Chuang, Integrating the Kano model into a robust design approach to enhance customer satisfaction with product design, International Journal of Production Economics, 114, 2008,667-681.

[8]. Wang, C. H., Apply robust segmentation to the service industry using kernel induced fuzzy clustering techniques, Expert Systems with Applications, 37(12), 2010,8395-8400.

[9]. Kwong, C. K., Y. Chen and K. Y. Chan, A methodology of integrating marketing with engineering for defining design specifications of new products, Journal of engineering Design, 22(3),2011, 201-213.

[10]. Berger, C., Blauth, R., Boger, D., Bolster, C., Burchill, G., DuMouchel, W., Pouliot, F., Richter, R., Rubinoff, A., Shen, D., Timko, M. and Walden, D., Kano's Methods For Understanding Customer-Defined Quality, The Center for Quality Management Journal 2(4), 1994,2-36.

[11]. Adila Md Hashim, Siti Zawiah Md Dawal, Kano model and QFD integration approach for ergonomic design improvement,Proc. The 20125 International (Summer) Conference on Business innovation and technology management",2015,22-32.

[12]. Qianli Xu, Roger J. Jiao, Xi Yang and Martin Helander, An analytical Kano model for customer need analysis, Design studies,30(1),2009,87-110.

[13]. Bilsen Bilgili, Aysel Ercis,Sevtap Unal,Kano model application in new product development and customer satisfaction(adaption of traditional art of tile making to jewelries, Proc. Social and behavioural sciences, $7^{\text {th }}$ International strategic management conference, 24,2011,829-846.

[14]. Rachna S. Singh, India's service sector- shaping future of Indian retail Industry,Proc.Economics and Finance,Symbiosis institute of management studies annual research Conference(SIMSARC13), 11,2004,314-322.Gérson Tontini, Integrating Kano model and QFD for Designing New Products, Total Quality Management, 18(6),2007, 599-612.

[15]. Ramaswamy, V., \& Ozcan, K., Brand value co-creation in a digitalized world: An integrative framework and research implications, International Journal of Research in Marketing (2015), http://dx.doi.org/10.1016/j.ijresmar.2015.07.001 